\title{
UNA EXPERIENCIA EN EL SEMINARIO DE DIDÁCTICA DE LA LENGUA DEL GRADO EN EDUCACIÓN PRIMARIA A TRAVÉS DEL SÉPTIMO ARTE
}

\section{An experience in Language Teaching Seminar of Primary Education Degree through the Seventh Art}

\author{
Angélica García-Manso \\ Universidad de Extremadura \\ Correo-e: angmanso@unex.es \\ Recepción: 25 de septiembre de 2016 \\ Envio a informantes: 25 de abril de 2017 \\ Aceptación definitiva: 28 de mayo de 2017
}

Resumen: El presente estudio describe el Seminario «Competencias Lingüísticas y Séptimo Arte» desarrollado en la Universidad de Extremadura en el curso 2015-2016. A través del análisis de una decena de filmes se abordan las competencias profesionales de los futuros maestros de Primaria a partir de situaciones singulares, en virtud de trastornos como la sordoceguera, el autismo o la dislexia; cuestiones sobre el origen de la lengua y las lenguas artificiales, o temas culturales como el del niño salvaje o en situaciones de aislamiento o soledad. Además de las consideraciones concretas sobre cada filme, se postula el uso activo del cine en diferentes ámbitos del aprendizaje de lenguas extranjeras y ELE.

Palabras clave: Didáctica de la Lengua; Cine; maestros de Educación Primaria; competencias.

Aвstract: This study describes the Seminar «Language Skills and Seventh Art» developed at the University of Extremadura in the course 2015-2016. Through the analysis of ten films, we deal with professional competences of future Primary teachers from unique situations, for example disabilities such as blind and deaf people, autism or dyslexia, questions about the origin of the language and artificial languages, or cultural issues such as the wild child or within situations of isolation or loneliness. In addition to the specific considerations of each film, the active use of Cinema in different areas of learning foreign languages and ELE (Spanish as Foreign Language) is postulated.

KeY WORds: Language Teaching; Cinema; Primary School teachers; competences. 


\section{Introducción y estado de la cuestión}

$\mathrm{E}$ N el Marco de los temas dedicados a las habilidades lingüísticas orales y de escritura de la asignatura de Didáctica de la Lengua del Grado en Educación Primaria (de carácter obligatorio, con 6 créditos ECTs, programada para el cuarto semestre) que se imparte en Facultad de Formación del Profesorado de la Universidad de Extremadura, se propuso a los estudiantes del curso 20I5-20I6 la realización de un Seminario monográfico dedicado a examinar el tratamiento que el cine hace de los procesos de aprendizaje para la adquisición del habla y la lectoescritura, así como de los obstáculos sociales, físicos y psicológicos para el logro de las competencias comunicativas al respecto. Su ámbito metodológico sería el de la exposición pública de los trabajos elaborados por los alumnos.

El recurso a las películas como herramienta didáctica en general (Martín Vegas, 2009) y, más en concreto, dirigida al estudiante universitario de Formación del Profesorado está suficientemente contrastado, tratándose de una práctica habitual (vv. AA., 20I3). Suele ofrecerse esta herramienta, no obstante, con un carácter complementario, cuando uno de los primeros resultados del desarrollo del Seminario refleja que se puede presentar como instrumento experimental de carácter central y abierto a perspectivas diferentes, que enriquecen la propiamente lingüística, que es objeto de atención primordial (Anulla, I997; Bautista, 2009; Linares y Hevia, 2013). Y ello al margen del aprendizaje de idiomas (sean extranjeros para el hispanohablante, sea como ELE -Español como Lengua Extranjera-), que acaparan gran parte de los estudios, análisis y propuestas didácticas con el cine como medio de enseñanza (Cuesta, 20II).

No obstante, las películas como vehículo de experiencias lingüísticas no deben abordarse con una consideración documental, como si el tratamiento de la lengua fuera un fin en sí mismo en el relato, sino concebirse como intermediación entre los objetivos expresamente cinematográficos y las claves de lectura aportadas por un receptor concreto: el estudiante del Grado de Educación Primaria. Dicha intermediación exige que se sitúe cada filme en el momento de su producción y de la vigencia de los postulados lingüísticos en las fechas en que se estrena la película. En otras palabras, la consideración del filme es tan importante como los contenidos lingüísticos que se desprendan de este por cuanto tales contenidos son abordados conforme a los conocimientos del momento en que se produce la película.

El autismo ofrece a este respecto una situación paradigmática, dado que podría decirse que la generalización del concepto de este trastorno en la sociedad se hace a través de la película Rain Man, del año I988; a posteriori cabría descubrir comportamientos autistas en personajes de numerosos filmes a lo largo de la Historia del Cine, pero no existía un dominio del concepto. Sucede con la base literaria de Los santos inocentes (1984, de Mario Camus), donde cabría analizar la competencia lingüística del personaje de Azarías, pero el peso que posee el texto literario de Delibes es tal que ni siquiera se plantea la posibilidad de percibir al personaje más que como retrasado mental, y los aspectos lingüísticos no van más allá de la reiteración del estribillo de «Milana bonita», sin explotarse como competencia la capacidad del personaje de reproducir los sonidos de los animales y la singularidad del lenguaje humano a este respecto. Y es que, desde la propia trama, la imposibilidad de reconocer esta circunstancia contribuyó al aislamiento socioeducativo del personaje. 


\section{Material y métodos}

La elección de los filmes del Seminario, hasta un total de diez en función del número de sesiones para impartirlo, parte de la premisa previa de la identificación del aspecto lingüístico objeto de análisis. Así, los extremos vendrían ocupados por filmes como En busca del fuego sobre los orígenes del lenguaje humano y Star Trek acerca de las lenguas artificiales (en particular el klingon; podría haberse hecho sobre el esperanto). Entre ambos extremos, títulos sobre el proceso de aprender a hablar (ciertamente aplicado sobre un adulto, como serían las situaciones genéricas de Robinson Crusoe y de Tarzán) hasta la sordoceguera patológica (con el consiguiente cambio a un modelo lingüístico no verbal), cuyo paradigma melodramático viene dado por $E l$ milagro de Anna Sullivan.

$\mathrm{La}$ incidencia que se hace en las diferentes formas de discapacidad no pretende destacar las competencias sociales y relacionales sobre las propiamente lingüísticas. En realidad, las pautas pedagógicas del aprendizaje coinciden en líneas generales con las que se producen en determinados procedimientos de actuación ante las discapacidades. Por ejemplo, el tartamudeo es tanto propio de un hándicap lingüístico como manifestación de aprendizaje mediante el silabeo en edades tempranas, según se puede apreciar en el filme, que recoge la historia de Kaspar Hauser o en Nell. Lo mismo cabe decir en relación con el autismo o la dislexia (Rain Man y Estrellas en la Tierra), donde los procesos reflejan al tiempo una percepción singular del entorno, una recreación que en ocasiones se podría calificar de poética, como en Nell. En fin, el ámbito de las competencias lingüísticas también es abordable desde perspectivas histórico-culturales, que explican la aparición de mitos como el del niño salvaje (en el que inciden, además, relatos literarios como, por ejemplo, el de Tarzán, en las distintas y numerosas versiones que se le han dedicado). De hecho, se han considerado filmes cuya trama al respecto de la competencia lingüística fueran abiertos (es decir, no monográficamente centrados en el tratamiento de la discapacidad y su consideración competencial), de forma que, de manera inevitable, han quedado fuera títulos, incluso de cinematografías tan próxima como la española, como, entre otros, los de Mater Amatísima (1980, de José Antonio Salgot), Los santos inocentes o El rey pasmado (I99I, de Imanol Uribe); o, en el caso de filmografías foráneas, filmes de éxito clásicos como Persona (1966, de Ingmar Bergman), adaptaciones como El nombre de la rosa (The Name of the Rose, 1986, de Jean-Jacques Annaud) o películas de índole más políticamente militante y comprometida como Mi pie izquierdo (My left Foot, 1989, de Jim Sheridan), alguno de los cuales pudiera retomarse en futuras ediciones del Seminario.

En la actualidad, el acceso a las películas no resulta difícil ni complejo. Se dejó directamente en manos del alumnado implicado, el cual puede tener más destrezas a este respecto que la propia responsable docente. En un orden de cosas distinto, los ochenta alumnos del curso se distribuyeron en dos seminarios de cuarenta alumnos y grupos de cuatro alumnos por filme, siendo los horarios de cada Seminario diferentes. De esta forma, en tanto los alumnos sólo percibían un único análisis de cada película, la profesora asistía a dos exposiciones. Se lograba compensar así el desequilibrio en la formación de los grupos, organizados por los propios alumnos, y el carácter desigual de las películas y su consiguiente interés intrínseco, a pesar de que se hubieran distribuido los filmes por sorteo. Finalmente, para las conclusiones en conjunto del Seminario se ha considerado la exposición más destacada de las dos 
dedicadas a cada película y los alumnos implicados han sido identificados únicamente mediante sus iniciales.

En la sesión inicial se ofrecieron los títulos y un único concepto, que definía desde perspectivas lingüísticas cada película.

- En busca del fuego (La Guerre du Feu, I981, de Jean-Jacques Annaud): orígenes del lenguaje humano.

- Star Trek III: En busca de Spock (Star Trek III: The Search for Spock, I984, de Leonard Nimoy): lenguas artificiales.

- Tarzán (Tarzan, 1999, de Chris Buck y Kevin Lima; otra opción hubiera sido la clásica The Ape Man, I932, de W. S. van Dyke): aprendizaje de una lengua.

- El pequeño salvaje (L'enfant sauvage, I970, de François Truffaut): procesos de adquisición de habilidades lingüísticas en un niño.

- Robinson Crusoe (1932, de A. E. Sutherland; otra posibilidad hubiera sido el filme Las aventuras de Robinson Crusoe/Robinson Crusoe, 1954, de Luis Buñuel): enseñanza de una lengua.

- El enigma de Kaspar Hauser (Jeder für sich und Gott gegen alle, 1974, de Werner Herzog): sobre adquisición de habilidades y competencias lingüísticas y sociales.

- Nell (i994, de Michael Apted): sobre la comunicación.

- El milagro de Anna Sullivan (The Miracle Worker, 1962, de Arthur Penn): discapacidad y lengua de signos.

- Rain Man (1988, de Barry Levinson): autismo.

- Estrellas en la Tierra (Taare Zameen Par, 2007, de A. Khan, A. Gupte y R. Madvhani): dislexia.

Se presentaron además siete aspectos que habían ser abordados en el análisis y la exposición, aunque se concedía a los alumnos la libertad de disponerlos de la forma que estimaran más idónea para sus objetivos, siempre que se hiciera constancia de todos los ítems recogidos en el siguiente esquema:

I) Pequeña descripción de la figura del director (nacionalidad, otras películas por él filmadas, algún apunte sobre su estética, etcétera), el género del filme (dibujos animados, drama, policíaco, película costumbrista, terror, fantasía, ciencia ficción, wéstern, entre otros), la corriente de la Historia del Cine en el que se inscribe la película (muda, blanco y negro, cine clásico de Hollywood, nuevos cines, cine digital...).

2) Sinopsis de la trama, de la estructura o partes del filme, personajes, ambientación, momento histórico del relato, etcétera.

3) Motivo lingüístico objeto de atención: orígenes del lenguaje humano, creación de una lengua, enseñanza o aprendizaje de la lengua, problemas de expresión, y todos los previamente señalados.

4) Fotogramas, secuencias o escenas en que aparece tal motivo en la película. Enumerar y sopesar su relieve en el conjunto de la película (por ejemplo, en virtud de la duración; o del número de personajes implicados; de los lugares donde se plantea el fenómeno lingüístico, etcétera).

5) Características del motivo: formas de hablar, aspectos lingüísticos (pronunciación, traducción, importancia del léxico, importancia de los gestos o ademanes, los sonidos, la escritura, el lugar de enseñanza, por citar algunos). 
6) Utilidad didáctica: reflexión acerca de qué competencia lingüística y educativa ofrece la película; qué soluciones adopta o pueden descubrirse; qué profesionales intervienen; al margen del filme, cuál es la aportación de la realidad sobre el relato.

7) Resultados y valoración personal.

Finalmente, los alumnos debían entregar un trabajo en el formato digital que estimaran conveniente: Word, Prezi, PowerPoint, PDF, AVI, etcétera, que debían colgar en plazo en el Aula correspondiente abierta en el Campus Virtual de la Universidad de Extremadura.

\section{Análisis y resultados}

Con el fin de no sobrecargar la presente exposición en lo que se refiere a los resultados obtenidos y el análisis de estos, nuestras reflexiones se centrarán en la caracterización del motivo lingüístico y en las competencias que de este se derivan. Acerca de la valoración personal, se insistió en general en la novedad que suponía el Seminario y en su jugosa repercusión para la formación como docentes de Enseñanza Primaria, y el agradecimiento por la iniciativa. De esta manera, y dejando al margen aspectos cinematográficos y de carácter coyuntural, los trabajos abordaron los aspectos y competencias que se especifican en los siguientes parágrafos.

\section{I. En busca del fuegor}

Los motivos centrales de la película de Annaud, es decir, la preservación del fuego por parte de un clan errante de humanos cuya fisonomía es más próxima a la que se atribuye a los neandertales que al grupo «sapiens» y el aprendizaje sobre cómo reavivarlo -en realidad, encenderlo-, se hacen corresponder con los procesos de comunicación y adquisición de habilidades lingüísticas por parte de los personajes. De esta manera, al abordarse de forma indirecta el origen del lenguaje humano, su carácter rudimentario hace que no se ofrezca una lengua comprensible para el espectador y que esta, tanto a los efectos lingüísticos como cinematográficos, aparezca fuertemente mediatizada con la gestualidad, es decir, con el uso de lenguaje no verbal (de acuerdo con los modelos ofrecidos por el antropólogo Desmond Morris, que aparece como asesor del filme, también en lo que a las formas de sexualidad se refiere). El lenguaje propiamente verbal avanza en el filme conforme se desarrolla el viaje de los protagonistas, desde la reproducción de sonidos animales y, sobre todo, onomatopeyas, hasta un nivel fonético paulatinamente más rico (Rivera, 2006), que se identifica con las posibilidades de supervivencia y el ejercicio del dominio sobre tribus y clanes menos evolucionados y, por lo tanto, con menor capacidad de cooperación y organización entre sus miembros. Por otra parte, dicho nivel prima la pronunciación gutural en un primer momento, para avanzar hacia sonidos más líquidos y agudos, como si el ser humano viviera un proceso de aprendizaje hacia las posibilidades de articular fonemas

Presentación mediante Avi con guion teatralizado en formato «youtuber» con el título de «Charla matinal». Alumnos que han elaborado el trabajo: IBF, CCP, JCCF, MIP y RCSP. 
desde la garganta hasta las oclusiones exteriores de la boca, como son labios y dientes (el escritor Anthony Burguess figura como asesor lingüístico en los créditos), de forma que las lenguas que se oyen en el filme poseen cierto aire a lenguas amazónicas y de los aborígenes australianos, aunque no exista correspondencia con estas ni ello signifique su condición de lenguas primitivas. La película es rica en la mostración de competencias asociadas al dominio del lenguaje verbal y, por supuesto, siguen vigentes la socialización, el trabajo en equipo, la posibilidad de emprender objetivos a largo plazo y, sobre todo, el enriquecimiento de las capacidades lingüísticas con el intercambio con grupos externos, ajenos a la tribu o clan. Pero también muestra cómo la lengua puede ser una herramienta de dominio y de poder.

\subsection{Start Trek III: En busca de Spock ${ }^{2}$}

La primera dificultad que ofrecía el título de Star Trek se refería a la elección del filme como objeto de trabajo, por cuanto se trata de una producción de enorme recorrido y éxito televisivo anterior a su explotación cinematográfica en forma de saga. La opción por el tercer episodio fílmico se basó en que su director era Leonard Nimoy, protagonista ya legendario del personaje del Dr. Spock y, por consiguiente, comprometido con el guion tanto desde delante como detrás de la cámara. El motivo lingüístico que se analizó se refería a las lenguas artificiales y su funcionamiento, que en un filme de ciencia-ficción adquieren la entidad de lenguas alienígenas o extraterrestres. En el filme objeto de estudio aparecen tres lenguas: la vehicular del filme (inglés, o español peninsular en la versión doblada), el «vulcano» y el «klingon». Apenas se puede considerar el estudio del «vulcano» en la película, dado su carácter minoritario en relación con el papel de los personajes y con un tratamiento menos trascendente en esta película frente al relieve que sí tiene el «klingon»; y ello a pesar de la procedencia «semivulcana» del Dr. Spock, cuyo apellido real es impronunciable para los humanos. El klingon, por su parte, posee entidad de lengua artificial, creada para la ficción por Marc Okrand, quien la caracterizó como un idioma extraño para los parámetros lingüísticos del inglés, y ello mediante dos recursos: uno fonético (con predominio de sonidos guturales no pertinentes fonéticamente en inglés) y un orden de palabras Objeto-Verbo-Sujeto, en la idea de mostrar una raza belicosa, con una percepción muy literal del entorno. En el análisis no se contemplaron aspectos alfabéticos ni de cultura escrita.

Las competencias que se derivan de la creación de una lengua artificial (Galán, 2009) son de carácter eminentemente metalingüístico (es decir, del uso de la lengua para analizar el funcionamiento de una lengua) y el reconocimiento de los elementos fonéticos, morfosintácticos y semánticos que la integran y que permiten incluso llegar a hacer un retrato del interlocutor.

\subsection{Tarzán}

Único filme en dibujos animados de los presentados en el Seminario. Los alumnos postularon que el filme ofrece a lo largo de su metraje cuatro caracterizaciones

Presentación mediante PowerPoint. Alumnos que han elaborado el trabajo: JJAC, RBR y PCM.

3 Presentación mediante AVI. Alumnos que han elaborado el trabajo: IAR, APM, LPF, LRC y RSG. 
lingüísticas. Estas afectan, en primer lugar, a la relación entre el lenguaje humano y el animal y, subsiguientemente, se puede ubicar en el debate sobre los orígenes del lenguaje; sucede con los sonidos que Tarzán emite cuando se encuentra entre los gorilas. La segunda caracterización se basa en las relaciones entre Tarzán y Jane, quien le enseña la lengua a partir de los métodos de repetición e imitación, con momentos divertidos por los equívocos que se producen. En tercer lugar, el aprendizaje mediante imágenes que se da cuando el profesor Porter utiliza un proyector ante Tarzán. Finalmente, el personaje negativo, el cazador, le hace dibujos para hacerse entender, como una rudimentaria forma de escritura. De esta forma, se avanza desde las onomatopeyas, las repeticiones fonéticas y las identificaciones simbólicas hasta, finalmente, la representación figurativa (Jarne, 2007).

\subsection{El pequeño salvaje}

Los alumnos se centraron en los métodos de repetición e imitación, de un lado, y de memorización y relación imagen/palabra, de otro -ello sin desestimar dentro del filme una educación de carácter social, sobre las formas de andar, de vestir, de comportarse, etcétera-, cuya aplicación hicieron extensiva desde el tema del niño abandonado o pequeño salvaje a los niños marginados; de ahí la trascendencia que concedieron a las competencias afectivas y de socialización, presentes en la figura del doctor Itard. Es decir, de alguna manera se trascendió la coyuntura del relato y de su faceta lingüística hacia aspectos éticos y sociológicos. El relato se presenta sobre una base histórica, conforme a una perspectiva que responde, de un lado, a la transición entre los siglos XVIII y xIX y, de otro, al momento de producción del filme, que reivindica una perspectiva menos convencional acerca de la individualidad y su sometimiento a las normas sociales. Se trata de una reivindicación que por su propia definición conlleva asociada la competencia de la asertividad mediante códigos lingüísticos y culturales (Melendo, 20II).

\subsection{Robinson Crusoes}

La elección del filme se basó en la primera realización sonora del relato de Defoe, a pesar de que se había propuesto también la versión de Luis Buñuel (Las aventuras de Robinson Crusoe, 1954) entre unas opciones que abarcaban desde producciones del cine silente hasta el denominado «blockbuster» actual (Robinson Crusoe, 1995, de R. Hardy y G. Miller). La propuesta de Buñuel respondía, además, a un momento central entre ambos extremos además de suponer para el director español una experiencia próxima a la del protagonista del relato: como un extraño que intenta adaptarse a la forma de trabajar de Hollywood sin comprender totalmente la cultura comercial inherente. El motivo lingǘstico que se descubre en la trama se basa en la enseñanza de un idioma a una persona que posee una lengua previa, sólo que esta

4 Presentación mediante PDF con enlaces a Youtube [https://www.youtube.com/watch?v=zrtW yL92II y https://www.youtube.com/watch? $\left.{ }=\mathrm{ixfP}_{2 \mathrm{Z}} \mathrm{Y}_{3} \mathrm{Vt}_{4}\right]$, en los que se reproducen escenas del filme. Alumnos que han elaborado el trabajo: BPM, MPB, ISG e IDVC.

s Presentación mediante PDF. Alumnos que han elaborado el trabajo: BVR, PGL y EGR. 
posee la consideración de aborigen, de lengua concebida errónea y apriorísticamente como atrasada. El mismo hecho de otorgar un nombre (Viernes) a quien posee su propio nombre, que se omite o silencia, implica un comportamiento de superioridad cultural que, además, no admite debate dentro del relato.

Una vez expuesta esta circunstancia, el método lingüístico que se aplica se basa en la repetición, de acuerdo con premisas conductistas, como las expresadas por B. F. Skinner. A este respecto son destacables tres escenas: el primer encuentro entre Robinson y Viernes, en el que prevalece la gestualidad; un segundo momento se produce mediante la expresión reiterativa de los nombres y la insistencia en que se trata de una relación pacífica, de «amistad»; finalmente, un tercer motivo se descubre cuando Viernes acepta su nuevo nombre y, por consiguiente, la nueva lengua a la que se somete tras recibir una recompensa o refuerzo positivo.

Con cada lengua se transmite una percepción singular del mundo, aunque, ciertamente, en Robinson prevalece una perspectiva colonial que, en el fondo y obsesionado con el retorno, le impide enriquecerse con las aportaciones de la parte colonizada (Moreno, 2006).

\subsection{El enigma de Kaspar Hauser ${ }^{6}$}

Se trata, de nuevo, de un filme de base histórica, sobre hechos del siglo xix, ante la aparición de un hombre en apariencia «no contaminado» en virtud del aislamiento que padeció desde niño para ocultar, acaso, unos orígenes espurios socialmente; de ahí que aparezca con una nota donde únicamente está escrito su nombre. Sin embargo, tal pureza choca con la necesidad de «humanizar» al sujeto para enseñarle no sólo a hablar, sino a caminar y sentarse de manera convencionalmente humana (Garrabé, 20I2), además de presentarlo ante terceros domesticado socialmente. Tres son las fases biográficas del aprendizaje lingüístico del personaje, asociadas a los lugares y las personas con las que convivió. Así, en un primer momento, se le enseña a pronunciar mediante silabeo su nombre y a dibujarlo más que a escribirlo de forma rudimentaria, como si la identidad lingüística y la identidad como individuo se presentaran como los dos lados de una misma moneda. En la etapa central del relato, el personaje, encerrado en una torre por la familia que lo acoge, aprende básicamente a través de la mímica, del gesto. Finalmente, a cargo de un aristócrata, descubre la expresión musical a través del piano. Sin embargo, los problemas de expresión van a ser permanentes, certificando acaso el fracaso de las tres propuestas. Y es que se descubre que la incomunicación responde a un aislamiento por carencia de habla y de coherencia de lo que se expresa; que esta puede derivar en actitudes violentas fruto de la impotencia a la hora de articular su pensamiento; o, en fin, que, a pesar de que la música se presenta como un idioma universal, también necesita unas destrezas de las que carece el protagonista. Se trata de una historia trágica, en la que subyace la cuestión de si alguna vez se llegó a reconocer quién era el personaje, como primera pauta de las habilidades de comunicación.

\footnotetext{
6 Presentación mediante PowerPoint. Alumnos que han elaborado el trabajo: cmv, MNR, AOO, BPS y
} FVF. 
La película se basa en una obra de teatro cuyo título ya es de por sí significativo desde la perspectiva del motivo lingüístico en juego: idioglosia, es decir, «lengua particular». Se trata de la lengua que crea, sin apenas contacto con el exterior, la protagonista, una joven que ha vivido aislada en un bosque junto a una madre afásica y una hermana gemela, que fallecen. La lengua que establecen entre sí las tres, hasta que Nell se queda sola, es una mezcla de farfullos y sonidos líquidos que esquivan las articulaciones consonánticas. La trama en sí en realidad afecta a los psicólogos encargados de valorar las capacidades de la joven y adquiere su punto culminante cuando se defienden en juicio sus derechos de regresar al entorno natural en el que se había criado. De esta manera, se respeta la percepción del mundo que tiene la chica, al tiempo que se reconoce la capacidad innata que poseen los seres humanos para establecer comunicación «paralingüística» e incluso procesos paralelos, como cuando los recuerdos se expresan mediante mímica (Ferreiro, 2003).

\subsection{El milagro de Ana Sullivan ${ }^{8}$}

La película se basa en la historia de Anne Sullivan, creadora de una de las lenguas de signos para discapacitados, a partir de la adaptación teatral de su biografía. La trama en sí aborda el problema de sordoceguera de la niña protagonista, Helen Keller, a quien sus padres intentan educar antes de llegar a la adolescencia, si bien la idea de educación de dichos padres coincide más con la de «domesticación» de un ser con el que no pueden establecer contacto. Anne, sin embargo, sí logrará comunicarse con Helen y hacerle aprender en varias fases un alfabeto manual-táctil, que elabora para ella a partir de su experiencia previa con niños ciegos, siendo el momento culminante -y también emocionante- cuando la niña comprende que el lenguaje humano se basa en la articulación de signos mediante el proceso de deletreo, que, en su caso, pasa por las figuras que crea con las diferentes posiciones de las manos.

Ante la cuestión de si la niña puede pensar, una de las claves competenciales que acerca de la comunicación se expresan en la película muestra cómo lengua y pensamiento constituyen las dos caras de una misma moneda. Así, Helen pide con ansiedad nuevas palabras, como su propio nombre, para organizar el entorno en el que le ha tocado vivir, y que, desde ese momento, pasará a integrar en su vida de forma consciente (Martínez, 2009).

\subsection{Rain $\mathrm{Man}^{9}$}

Según hemos señalado en un epígrafe previo, la importancia pedagógica del filme al respecto de las habilidades y competencias lingüísticas radica también en que, de alguna manera, se trata de la película que dio a conocer el autismo al espectador no

7 Presentación mediante PDF. Alumnos que han elaborado el trabajo: IRM, MSM, DY y PTD.

8 Presentación mediante PowerPoint, con inserción de breves escenas del filme en vídeos integrados en las diapositivas. Alumnos que han elaborado el trabajo: LCS, JCS, AMCR, MAGG-C y MGB.

9 Presentación mediante PowerPoint. Alumnos que han elaborado el trabajo: MAPD, NMC, FVG y osy. 
especializado, es decir, al gran público. Lo hizo, además, en unos momentos en los que la misma teoría educativa sobre cómo afrontar los casos de autismo y la amplitud de su espectro se encontraba en sus inicios. Por otra parte, estadísticamente el autismo suele ser, junto con la dislexia -y dejando a un lado la especificidad del Síndrome de Down, perceptible externamente-, la manifestación más habitual en las aulas de alumnos con necesidades específicas. Por lo demás, en el conjunto del Seminario se trata del filme que más interés y participación suscitó.

El filme aborda el fenómeno del autismo desde el contraste entre una percepción singular del mundo (que precisa de rutinas, de espacios conocidos y de situaciones de calma) y la propia de una sociedad normal entre comillas, repleta de azares, de novedades y de estrés (Tordera, 2007). La oposición se dramatiza en la forma de vida de dos hermanos que se conocen y se aceptan tras décadas sin saber el uno de otro (de hecho, el protagonista «normal» ignoraba la existencia de un hermano mayor). Se destacan varias escenas que oponen sendas perspectivas y cómo, al cabo, el personaje autista puede adaptarse a situaciones normales que él vive como absurdas y a la inversa. De ahí que se decida, al final, su retorno al sanatorio, que constituye su ambiente normalizado.

Desde perspectivas lingüísticas, desde el propio título se ofrece la interrelación palabra y vivencias según la percibe una persona autista: Raymond es «Rain Man», el hombre-lluvia, motivo que provocó que el padre internara al hijo especial, que casi ahoga a su hermano pequeño al intentar bañarlo, pues, literalmente, su nombre sería el de «lluvia». La literalidad es una de las características del espectro autista, así como la falta de atención por aquello que no comprende o la existencia de habilidades mnemotécnicas y de cálculo ensimismadas, por cuanto no resultan útiles en lo cotidiano. Así, las personas del espectro autista pueden aprender perfectamente a leer, aunque pueden no comprender el sentido de lo escrito (de hecho, su lectura es monocorde, nada expresiva); la escritura, sin embargo, suele ser más torpe y, en lo que al habla se refiere, su repertorio léxico y sintáctico no es amplio, pues la organización de su pensamiento evita la abstracción y suele funcionar mediante asociaciones de objetos y espacios. De hecho, como bien encarna el actor en el filme, predomina la demora en el flujo del habla, la insistencia en la reiteración de las palabras y, en ocasiones, el tartamudeo, si bien tales factores son precisamente los que facilitan su aprendizaje lectoescritor: la lentitud, la repetición y el silabeo.

Como el abanico de grados del autismo (de hecho, en la actualidad se prefiere la expresión «espectro autista») es amplio, las capacidades de integración y comunicación reflejan bastante diversidad, aunque siempre bajo la premisa de que son perfectamente posibles con sus singularidades específicas. En este sentido, la propuesta del final del filme resulta un tanto conservadora, pues prefiere la atención asistida del protagonista en un entorno aislado a su adaptación en ambientes más abiertos.

\subsection{Estrellas en la tierra ${ }^{10}$}

Se trata del filme de producción más exótica en el conjunto de los estudiados en el Seminario, si bien, aunque sea de origen hindú, su contenido es perfectamente trasladable a los parámetros occidentales. La trama aborda el fracaso escolar de un niño

ı Presentación mediante PowerPoint. Alumnos que han elaborado el trabajo: JCN, JMG, GPG y APC. 
y sus reacciones agresivas a pesar de su gran creatividad artística en el ámbito de una familia acomodada, con reconocimientos intelectuales y académicos destacados. Solamente su profesor de dibujo descubre cuál es su problema: la dislexia. Y lo descubre no sólo porque la persona con déficit disléxico percibe el mundo con unos paradigmas más visuales y figurativos que abstractos y simbólicos, sino porque él mismo tiene esa característica intelectual. De hecho, si se dedica al dibujo es, precisamente, como forma de comprender su entorno desde las imágenes y no desde los textos. De cualquier forma, los disléxicos pueden dominar perfectamente la lectoescritura; varían los procesos de aprendizaje, que son de carácter más físico, más táctil (de ahí los recursos a escribir sobre la arena, al modelado tridimensional de las letras, entre otros); y, sobre todo, separando el grafismo de las tipografías, preferiblemente no manuales.

La primera víctima de la dislexia es la autoestima de la persona que posee esta característica; la ayuda únicamente se puede prestar desde una profunda empatía con la persona disléxica, además de bastante dosis de paciencia con la aparente lentitud de sus progresos (Dehaene, 20I4). El filme aborda este aspecto desde el papel pedagógico del profesor, que explica al conjunto de la clase sus características, además de crear un listado de personas célebres que poseen esta forma de percibir la realidad. El procedimiento, por lo tanto, es el de integración -por cuanto el niño se mantiene en su aula- y el de presentación de modelos de superación -no sólo personas destacables, sino el mismo profesor-. Finalmente, la potenciación de las habilidades artísticas que, a pesar de la dislexia o gracias a esta, posee el niño, se convierte en la solución a su autoestima, destacándose de este modo el carácter creativo de cada individuo.

\section{Discusión y conclusiones}

Al margen de su aplicación en lenguas extranjeras y ELE, el Seminario ha demostrado cómo el uso de filmes en el aula para una asignatura de contenidos lingüísticos se presenta como una herramienta eficaz en dos sentidos: en primer lugar, para los contenidos de la materia desde una perspectiva práctica; y, en segundo lugar, como una forma de ejercicio y análisis para los estudiantes a la hora de abordar el estudio de las películas. No obstante, a la hora de documentar los contenidos a partir de la película la fuente suele ser "Wikipedia», sin que se haya pedido bibliografía específica a la docente, a pesar del ofrecimiento de esta. Es como si la propuesta de trabajo sobre cada filme colmara las expectativas de los estudiantes toda vez que habían de cumplimentar siete campos, a pesar de que, en realidad, solamente eran dos los que interesaban doctrinalmente para la materia. Además, en ningún caso se argumentó metodológicamente el sistema de presentación propuesto. De ahí, en buena medida, los resultados desiguales, sobre todo en aquellos grupos de alumnos que no percibieron que la primacía del enfoque no estaba en el filme, sino en los contenidos lingüísticos.

El esfuerzo por localizar las escenas de carácter lingüístico se reflejaba en la selección de secuencias intercaladas en las presentaciones, y constituía, además, el argumento central para llevar a cabo el Seminario. En relación con el ámbito de las competencias que se podían descubrir de los motivos lingüísticos de tales escenas, solía prevalecer una lectura de carácter ético, es decir, sobre el respeto a la singularidad sin 
menoscabo de la igualdad de oportunidades. Se trata de una respuesta "políticamente correcta», o una captatio benevolentiae tanto hacia compañeros como hacia la profesora, si bien, en ocasiones, sí aparecía argumentada con ejemplos paralelos al margen del filme (que era lo que se proponía realmente), para no quedar la competencia agotada en su mera enunciación.

Ya en el ámbito concreto de los aspectos lingüísticos, el esfuerzo central se dirigió a ubicar en los contenidos teóricos de la asignatura los temas que se descubrían, desde las distintas teorías sobre el origen del lenguaje humano hasta las técnicas de lectoescritura en situaciones excepcionales. En el terreno de las competencias, los relatos fílmicos se convertían en una especie de campo de pruebas verosímil (a pesar de su carácter ficticio) sobre la importancia de la comunicación en los seres humanos, aunque ello se llevaba a cabo sin crítica hacia las posturas que se reflejaban en los filmes, a pesar de que algunos de estos quedaban singularmente abiertos hacia debates de otra índole (caso de los filmes de Truffaut y de Herzog).

Finalmente, y desde una perspectiva metodológica, la «anécdota» de las escenas lingüísticas se convertía, en el proceso del Seminario, en clave de lectura de la película en su conjunto. En ocasiones, dicha clave resultaba original hasta el punto de enriquecer la interpretación de los filmes (es decir, indirectamente, también el Seminario permite una aproximación transversal hacia el Séptimo Arte).

\section{Bibliografía $^{\text {II }}$}

Anulla Rebollo, A. (1997) Teoría lingüística y evaluación de la competencia gramatical en sujetos con trastornos profundos del desarrollo. Didáctica (Lengua y Literatura), 9, 39-66.

Bautista García-Vera, A. (2009) Relaciones interculturales en educación mediadas por narraciones audiovisuales. Comunicar, 33, I49-156.

Benítez-Burraco, A. (2012) ¿Es el lenguaje (complejo) el resultado de una transferencia genética entre neandertales y humanos modernos? Trabajos de Prehistoria, 69, 2I2-23I.

Bueno Ramírez, P.; Balbín Behrmann, R. de y Alcolea González, J. J. (2003) Prehistoria del lenguaje en las sociedades cazadoras y productoras del sur de Europa. En P. Bueno Ramírez y R. de BAlBín Behrmann (coords.) El arte prehistórico desde los inicios del siglo XXI: Primer Symposium Internacional de Arte Prebistórico de Ribadesella (pp. 13-22). Santander: Asociación Cultural de Amigos de Ribadesella.

Camacho, J. L. (2003) Ver/Imaginar, el niño y el salvaje: el modernismo, la percepción del color y la evolución de los sentidos. Confluencia: Revista Hispánica de Cultura y Literatura, I8, 32-4I.

Cuesta Estévez, G. J. (20II) Del texto cinematográfico al aula: un curso de lengua y sociedad a través del cine español. En J. de Santiago Guervós, H. Bongaerts, J. J. Sánchez Iglesias y M. Seseña Gómez (eds.) Del texto a la lengua: La aplicación de los textos a la enseñanza-aprendizaje del español L2-LE (pp. I039-IO49). Salamanca: Asociación para la Enseñanza del Español como Lengua Extranjera.

Dehaene, S. (20I4) El cerebro lector. Últimas noticias sobre neurociencias de la lectura, la enseñanza, el aprendizaje y la dislexia. Buenos Aires: Siglo xxi Editores.

Ferreiro Lago, E. (2003) Signos de película: la lengua de signos en el cine. Faro del Silencio: la Revista de Todas las Personas Sordas, 193, 16-21.

"La que aquí se desglosa es, aparte de las obras referenciadas en el texto, la bibliografía recomendada por el profesor y manejada por los alumnos para la realización de los distintos trabajos de investigación. 
Flores Coll, M. y Durán Gisbert, D. (20I3) Leemos en pareja: desarrollo de la competencia lectora a través de la tutoría entre iguales. En Actas del Congreso Iberoamericano de las Lenguas en la Educación: Las lenguas en la educación, cine, literatura, redes y nuevas tecnologías (pp. 259-266) Madrid: Ministerio de Educación, Cultura y Deporte. Recuperado el 20 de septiembre de 20I6, de https://sede.educacion.gob.es/publiventa/descarga.action?f_codigo_agc $=$ I6I84.

GALÁn Rodríguez, C. (2007) Logomaquias y logofilias: distopías lingüísticas en la ficción literaria. Anuario de Estudios Filológicos, 30, II5-129.

GALÁn Rodríguez, C. (2009) La invención de lenguas en la ficción literaria. Estudios de Lingüistica. Universidad de Alicante: E.L.U.A., 3, I03-130.

García-Manso, A. (2017) La leyenda de Gösta Berling: una propuesta didáctica desde la interrelación literatura/cine. Tejuelo, 26 [en prensa].

Garrabé, J. (20I2) El niño salvaje. Maremagnum: Publicación galega sobre os trastornos do espectro autista, I6, I37-I49.

Janer Manila, G. (2003) La invención literaria de la infancia: del niño salvaje al niño prodigio. En L. M. Naya Garmendia y P. Dávila Balsera (eds.) La infancia en la historia: espacios y representaciones, vol. 2 (pp. 763-775). San Sebastián: Erein.

Jarne Esparcia, A. J. (2007) Tarzán de los monos. Making of: Cuadernos de Cine y Educación, 5O, 67-73.

Linares Cardoso, C. y Hevia Artime, I. (2013) Educacine: competencias y posibilidades del uso del cine como medio narrativo en entornos educativos. En Actas del Congreso Iberoamericano de las Lenguas en la Educación: Las lenguas en la educación, cine, literatura, redes y nuevas tecnologías (pp. 6I-69). Madrid: Ministerio de Educación, Cultura y Deporte. Recuperado el 20 de septiembre de 2016, de https://sede.educacion.gob.es/publiventa/descarga.action?f_codigo_agc $=16184$.

Martín Vegas, A. R. (2009) Manual de Didáctica de la Lengua y la Literatura. Madrid: Síntesis.

Martínez Abellán, R. (2009) Sullivan y Keller: su lucha por los discapacitados sensoriales. Sevilla: MAD.

Martínez Alonso, M. B. y Gómez Conde, L. (2012) Entre la pedagogía y la psicopatología: el niño salvaje en el nacimiento de la psiquiatría infantil. Maremagnum: Publicación galega sobre os trastornos do espectro autista, 16, 177-190.

Martos Pérez, J. y Pérez Juliá, M. (2002) Autismo: un enfoque orientado a la formación en logopedia. Valencia: Nau Llibres.

Melendo Cruz, A. (20II) De El pequeño salvaje de François Truffaut al niño asilvestrado de Gerardo Olivares. En P. Poyato Sánchez (ed.) Paisajes del cine rural español: IX muestra de Cine Rural en Dos Torres (Córdoba) (pp. 24I-275). Córdoba: Universidad de Córdoba/ Diputación de Córdoba/Ayuntamiento de Dos Torres.

Mendoza, E. y Muñoz, J. (2005) Del trastorno específico del lenguaje al autismo. Revista de Neurología, 4I, 9I-98.

Moreno Cabrera, J. C. (2006) La lengua de Viernes: Robinson Crusoe y el colonialismo lingüístico. En VII Congrès de Lingüístic General. Barcelona: Universitat de Barcelona.

Morris, D. (2003) El mono desnudo. Barcelona: DeBolsillo (I. ${ }^{a}$ ed. en español de 1967).

Okrand, M. (1997) Klingon for the Galactic Traveler. New York: Pocket Books.

Rivera Arrizabalaga, Á. (2006) Conducta y lenguaje en la Prehistoria. Arqueoweb: Revista sobre Arqueología en Internet, 8. Recuperado el 20 de septiembre de 20I6, de http://pendientedemigracion.ucm.es/info/arqueoweb/pdf/8-I/rivera.pdf.

Rodríguez MuÑoz, F. J. (2007) Comunicación, autismo y síndrome de Asperger: hacia un estado de la cuestión desde el punto de vista bibliográfico. Tonos Digital: Revista Electrónica de Estudios Filológicos, I3. Recuperado el 20 de septiembre de 2016, de http://www.um.es/ tonosdigital/znumı/secciones/estudios_Y_AUTISMO\%20ASPERGER.htm. 
Tordera Yllescas, J. C. (2007) Trastorno de Espectro Autista: Delimitación Lingüística. Estudios de Lingüistica de la Universidad de Almería: E.L.U.A., 2I, 30I-3I4.

vv. AA. (2013) Actas del Congreso Iberoamericano de las Lenguas en la Educación: Las lenguas en la educación, cine, literatura, redes y nuevas tecnologías. Madrid: Ministerio de Educación, Cultura y Deporte. Recuperado el 20 de septiembre de 20I6, de https://sede.educacion.gob. es/publiventa/descarga.action?f_codigo_agc $=16184$.

Yela Fernández, O. R. (2007) El cine como laboratorio en el aula: una revisión semiótica de la película La lengua de las mariposas. Foro de Educación, 9, 99-I24. 